\title{
Amino-starch Nanoparticles as Controlled Release Nanocarriers for Curcumin
}

\author{
Lionel Victor Kemin and Suk-Fun Chin* \\ Faculty of Resource Science and Technology, Universiti Malaysia Sarawak, \\ 94300 Kota Samarahan, Sarawak, Malaysia \\ ${ }^{*}$ Corresponding author: sfchin@unimas.my
}

Published online: 25 August 2020

To cite this article: Kemin, L. V. \& Chin, S-F. (2020). Amino-starch nanoparticles as controlled release nanocarriers for curcumin. J. Phys. Sci., 31(2), 1-14. https://doi. org/10.21315/jps2020.31.2.1

To link to this article: https://doi.org/10.21315/jps2020.31.2.1

\begin{abstract}
Curcumin is a naturally occurring phytochemical with interesting therapeutical properties. However, it shows some limitations of low intrinsic solubility, fast degradation and poor bioavailability. In this study, curcumin was loaded onto aminofunctionalised starch (amino-starch) nanoparticles via the nanoprecipitation method in an attempt to increase its water solubility. In this nanoprecipitation process, the aminostarch aqueous solution was added into excess ethanolic solution under stirring. Aminostarch nanoparticles were formed as organic solvent got separated from the amino-starch. Amino-starch nanoparticles with mean particle size of $163 \mathrm{~nm}$ were obtained by dropwise addition of dissolved amino-starch solution into excess absolute ethanol solution containing curcumin. Amino-starch nanoparticles showed enhanced curcumin loading capacity of $0.76 \mathrm{mg} \mathrm{mg}^{-1}$ as compared to $0.33 \mathrm{mg} \mathrm{mg}^{-1}$ for native starch nanoparticles. Curcumin was observed to release out slowly from amino-starch nanoparticles over a period of $12 \mathrm{~h}$. Therefore, the potential of amino-starch nanoparticles as the controlled release nanocarriers for curcumin was demonstrated.
\end{abstract}

Keywords: Amino-starch, starch nanoparticles, curcumin, nanocarriers, starch

\section{INTRODUCTION}

Curcumin is a naturally occurring phytochemical derived from Curcuma longa (turmeric) with interesting therapeutic properties, including being antioxidant, anti-inflammatory, anti-proliferative, anti-microbial, as well as the antitumor effect for many types of cancer cells. ${ }^{1}$ It has been reported to have a minimal side effect on humans, and it is still safe for consumption even at a higher dosage. ${ }^{2}$ 
Despite all these promising biomedical properties, curcumin suffers from several limitations such as low water solubility, fast degradation and poor bioavailability. Consequently, various research efforts were carried out to load curcumin onto nanocarrier to enhance its water solubility, stability and bioavailability., ${ }^{1,3}$

Starch nanoparticles have been demonstrated to be promising nanocarriers for various drugs and nutraceutical products as they are composed of a natural polysaccharide that is renewable, biodegradable, low cost, abundantly available and biocompatible with tissue and cells. ${ }^{4}$ Previously, our research group has loaded curcumin onto native starch nanoparticles by the in-situ precipitation microemulsion method. However, the intrinsic poor water solubility of native starch has resulted in a relatively low loading capacity of curcumin. Higher loading capacity of curcumin was achieved by the use of a microemulsion method, which was due to higher suspension stability of starch that afforded more curcumin to be encapsulated onto the starch nanoparticles. ${ }^{1}$

Amino-starch mostly had been reported to show enhanced physical properties such as higher water solubility, aside from exhibiting low antimicrobial properties. $^{5}$ The protonation of the amino groups facilitates the repulsion between the polymer chains, forming a stable starch suspension in aqueous solution. ${ }^{2}$ Thus, improved hydrophilic properties of native starch will also help to increase the loading capacity of curcumin onto the starch nanoparticles. In this study, amino-starch was synthesised by reacting native sago starch (Metroxylon sagu) with ethylenediamine in the aqueous-based medium and subsequently loaded with curcumin via the in-situ nanoprecipitation method. The prepared curcumin loaded amino-starch nanoparticles then were evaluated as controlled release nanocarriers of curcumin.

\section{EXPERIMENTAL}

\subsection{Materials}

Native sago starch was purchased from a local grocery store in Kuching (Sarawak, Malaysia). Ethylenediamine from R\&M Chemicals (United Kingdom) as an amino source, epichlorohydrin from Sigma Aldrich (United States) as the crosslinking agent, and curcumin powder from Merck (Germany) were used. Sodium hydroxide $(\mathrm{NaOH})$ was obtained from Merck (Germany), ethanol was obtained from HmbG Chemicals (Malaysia), potassium bromide $(\mathrm{KBr})$ of infrared spectroscopy grade was from Merck (Germany), and hydrochloric acid was obtained from R\&M Chemicals (United Kingdom). All chemicals were reagent grade and used as 
purchased without further purification. All aqueous solutions were prepared using ultrapure water $\left(\sim 18.2 \mathrm{M} \Omega, 25^{\circ} \mathrm{C}\right)$ from the Water Purifying System, ELGA, Model Ultra Genetic (United Kingdom).

\subsection{Preparation of Amino-starch Nanoparticles}

Amino-starch nanoparticles were prepared based on the methodology reported by Wang et al. ${ }^{6}$ Native sago starch was dried for $2 \mathrm{~h}$ at $60^{\circ} \mathrm{C}$ prior to use. A starch solution $(2 \% \mathrm{w} / \mathrm{v})$ was prepared by dissolving $1.0 \mathrm{~g}$ of native sago starch in $50 \mathrm{ml}$ of $1.0 \mathrm{M}$ aqueous sodium hydroxide $(\mathrm{NaOH})$ solution at $70^{\circ} \mathrm{C}$. Approximately $0.1 \mathrm{ml}$ epichlorohydrin was then added and the mixture was continuously stirred overnight. The resulting solution was adjusted to $\mathrm{pH}$ 6-7 with hydrochloric acid $(\mathrm{HCl})$ and successively $1.0 \mathrm{ml}$ of ethylenediamine was added. The aqueous amino-starch solution was then re-precipitated by stirring at $500 \mathrm{rpm}$ in absolute ethanol to form amino-starch nanoparticles. After centrifugation, the supernatant was removed and the regenerated amino-starch nanoparticles were washed three times with absolute ethanol to remove excess $\mathrm{NaOH}$, epichlorohydrin and ethylenediamine. A clear solution of supernatant was observed after washing three times with the absolute ethanol.

\subsection{Preparation of Curcumin Loaded Amino-starch Nanoparticles}

Curcumin was loaded onto the amino-starch nanoparticles via the in-situ nanoprecipitation method as reported by Chin et al. ${ }^{1}$ Amino-starch solution with $1 \%(\mathrm{w} / \mathrm{v})$ concentration was prepared by a constant stirring of $0.25 \mathrm{~g}$ amino-sago starch in $25 \mathrm{ml}$ ultrapure water at ambient temperature. Curcumin powder then was dissolved in $20 \mathrm{ml}$ of absolute ethanol, making up $7.5 \mathrm{mg} \mathrm{ml}^{-1}$ of solution concentration by continuously stirred until a homogenous solution was obtained. An amount of $1 \mathrm{ml}$ aliquot of the starch solution was added dropwise into the curcumin ethanol solution and stirred for another $30 \mathrm{~min}$. Curcumin was loaded in-situ as the amino-starch nanoparticles were formed during the precipitation process. The curcumin loaded amino-starch nanoparticles were collected by centrifugation and washed three times with absolute ethanol in order to remove excess curcumin adhered to the surface of the nanoparticles.

\subsection{Loading Capacity of Curcumin}

The curcumin loaded amino-starch nanoparticles were collected by centrifugation and the amount of free curcumin in the supernatant was measured by a UV-Vis spectrophotometer at a wavelength of $429 \mathrm{~nm}$. A calibration curve of curcumin in absolute ethanol within the concentration range of $1.5 \mathrm{mg} \mathrm{l}^{-1}$ to $15 \mathrm{mg}^{-1}$ was used 
to determine the amount of curcumin loaded onto the amino-starch nanoparticles. The loading capacity of curcumin $\left(\mathrm{mg} \mathrm{mg}^{-1}\right)$ was calculated based on Equation 1:

$$
\frac{\text { curcumin }_{\text {(initial) }}-\text { curcumin }_{\text {(free) }}}{\text { total weight of nanoparticles }}
$$

where curcumin $_{\text {(initial) }}$ is the initial concentration of curcumin used before encapsulation and curcumin (free) $_{\text {is }}$ ise concentration of curcumin available in the supernatant after centrifugation.

\subsection{Curcumin Release Study}

Curcumin release study was conducted based on the methodology reported by Voon et al., ${ }^{719}$ About $50 \mathrm{mg}$ of curcumin loaded amino-starch nanoparticles were dispersed in $15 \mathrm{ml}$ of phosphate-buffered saline (PBS) at two different $\mathrm{pH}$ values: (1) $\mathrm{pH} 7.4$ which simulate human blood; and (2) $\mathrm{pH} 1.2$ which simulated gastric juice. ${ }^{89}$ PBS medium of $\mathrm{pH} 1.2$ was prepared by adding diluted $\mathrm{HCl}$ to the desired $\mathrm{pH}$ value. The desired medium $\mathrm{pH}$ value of PBS for $\mathrm{pH} 1.2$ was adjusted by adding diluted $\mathrm{HCl}$. Curcumin release study suspension was kept incubated at $37^{\circ} \mathrm{C} \pm 0.5^{\circ} \mathrm{C}$, at a scheduled time interval $5 \mathrm{ml}$ of PBS solution was withdrawn and then replaced with an equal volume of PBS solution of the same $\mathrm{pH}$. The amount of curcumin released was quantified by measuring its absorbance by the UV-Vis spectrophotometer at the wavelength of $429 \mathrm{~nm}$. The calibration curve of curcumin was constructed beforehand by measuring a series of curcumin standards in PBS at $429 \mathrm{~nm}$. The concentration of the curcumin released then was calculated with reference to the calibration curve $\left(\mathrm{R}^{2}=0.997\right.$ at $\mathrm{pH} 1.2, \mathrm{R}^{2}=0.959$ at $\mathrm{pH}$ 7.4) of curcumin in PBS. The percentage of curcumin released from aminostarch nanoparticles was calculated based on Equation 2:

$$
\frac{\text { Mass of curcumin released }}{\text { Mass of curcumin in nanoparticles }} \times 100 \%
$$

\subsection{Swelling Study}

The swelling behaviour of amino-starch nanoparticles was studied by dispersing the amino-starch at two different $\mathrm{pH}$ values $(\mathrm{pH} 7.4$ and $\mathrm{pH} 1.2)$. Amino-starch nanoparticles were immersed in the $10 \mathrm{ml}$ of buffer at $\mathrm{pH} 7.4$ and $\mathrm{pH} \mathrm{1.2,}$ respectively at $37^{\circ} \mathrm{C} \pm 0.5^{\circ} \mathrm{C}$. At predetermined time intervals, the nanoparticles were removed, and the excess buffer was blotted with filter paper. Changes in the weight of the swollen nanoparticles were measured and recorded. The experiment was conducted for $8 \mathrm{~h}$ as swelling of nanoparticles has reached equilibrium. 
The mass of nanoparticles remained constant after $8 \mathrm{~h}$. The swelling ratio was calculated based on Equation 3:

$$
\frac{W_{w}-W_{d}}{W_{d}}
$$

where $W_{w}$ and $W_{d}$ are the wet and dry weights of amino-starch nanoparticles.

\subsection{Characterisation of Amino-starch and Curcumin Loaded Amino- starch}

\subsubsection{FTIR spectroscopy}

The samples were mixed with $\mathrm{KBr}$ with a ratio of 1:100 to form pellets. The sample/KBr pellets were scanned using the FTIR spectroscopy, Thermo Scientific/Nicolet iS10 (United States) within the wavenumber range of $4000-500 \mathrm{~cm}^{-1}$.

\subsubsection{SEM}

The morphological characterisation of samples was conducted by using a scanning electron microscope (SEM), JEOL JSM-639OLA (Japan), at an accelerated voltage of $10 \mathrm{kV}$.

Samples were dried in an oven for $12 \mathrm{~h}$ at $60^{\circ} \mathrm{C}$ before mounting it on metal stub using conductive carbon tape. The gold coating then was applied to the mounted sample to further increase the conductivity before viewing it under the scanning electron microscope.

\subsubsection{UV-Vis spectroscopy}

The loading capacity and release study of curcumin was determined using a UV-Vis spectrophotometer, Perkin Elmer Lambda 25 (United States) by measuring the absorbance at the wavelength of $429 \mathrm{~nm}$. A calibration standard curve of curcumin was plotted by measuring the absorbance of a series of curcumin solutions of different concentrations. 


\section{RESULTS AND DISCUSSION}

\subsection{FTIR Analysis}

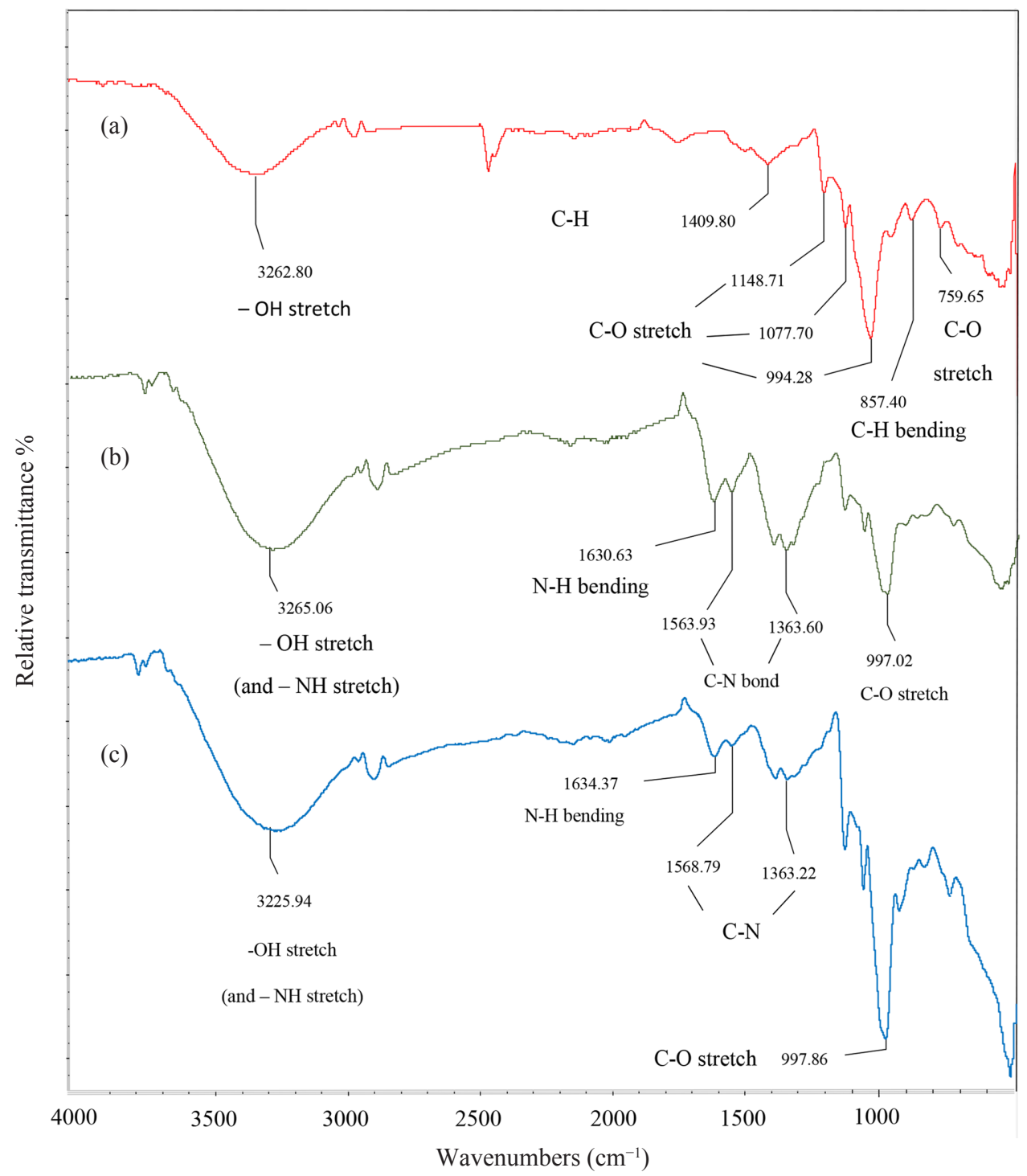

Figure 1: FTIR spectra of (a) native sago starch, (b) amino-starch, and (c) amino-starch nanoparticles. 
FTIR spectra of native sago starch and amino-starch are shown in Figure 1. Figure 1(a) shows absorption peaks at $1409 \mathrm{~cm}^{-1}$ and $857 \mathrm{~cm}^{-1}$ which were attributed to $\mathrm{C}-\mathrm{H}$ bendings, whereas peaks at $1148 \mathrm{~cm}^{-1}, 1077 \mathrm{~cm}^{-1}, 994 \mathrm{~cm}^{-1}$ and $759 \mathrm{~cm}^{-1}$ were due to stretching vibration of $\mathrm{C}-\mathrm{O}$ bonds. ${ }^{10}$ All absorption peaks observed were a general characteristic of any starch samples with a peak at $759 \mathrm{~cm}^{-1}$ being solely attributed to starch molecules. ${ }^{10}$ Strong absorption peak at $3262 \mathrm{~cm}^{-1}$ was also observed in Figure 1(a) which belongs to -OH stretching of native sago starch molecules. Figure 1(b) shows amino-starch with closely similar peaks observed at $3265 \mathrm{~cm}^{-1}$, due to the $-\mathrm{OH}$ stretching overlapped with NH stretching in the same region. ${ }^{2,11}$ Absorption peak observed at $997 \mathrm{~cm}^{-1}$ which resembles $994 \mathrm{~cm}^{-1}$ peak in Figure 1(a) also belongs to the stretching of C-O bonds of the starch molecule. A strong peak was observed at $1630 \mathrm{~cm}^{-1}$ which was attributed to the N-H bending vibration. ${ }^{2}$ A new weak peak was also observed around $1563 \mathrm{~cm}^{-1}$ and $1363 \mathrm{~cm}^{-1}$, due to the $\mathrm{C}-\mathrm{N}$ bond in between the amino group and starch molecules. ${ }^{12,13}$ The presence of these peaks evidenced that amino groups were successfully attached to the starch molecules. Figure 1(c) shows the FTIR spectra of the prepared amino-starch nanoparticles. It is closely similar to Figure 1(b) which implies that there is no changes occur on the functional group even after the formation of nanoparticles.

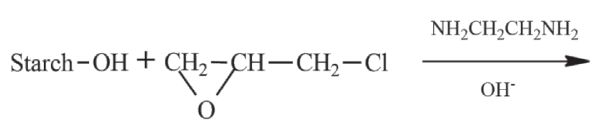

$$
\begin{aligned}
& \begin{array}{c}
-\mathrm{Starch}-\mathrm{O}-\mathrm{CH}_{2}-\mathrm{CH}-\mathrm{CH}_{2}-\mathrm{NH}-\mathrm{CH}_{2}-\mathrm{CH}_{2}-\mathrm{NH}-\mathrm{CH}_{3} \\
\mathrm{OH}
\end{array}
\end{aligned}
$$

Figure 2: Proposed schematic representation of the reaction of amine and native sago starch to form amino-starch.

Figure 2 shows the proposed schematic representation of the reaction for the formation of amino-starch. ${ }^{6}$ The low reactivity of native sago starch and amine requires modification in order to improve inter-reactivity between the compounds. Therefore, epichlorohydrin was used as a crosslinking agent, producing starchether. ${ }^{14}$ In the presence of excess epichlorohydrin, starch-ether could react efficiently with ethylenediamine in which aminated starch was obtained. ${ }^{15}$

\subsection{Morphological Study}

Figure 3 shows the SEM micrographs of native sago starch and amino-starch nanoparticles. Granule's size distribution was analysed by using SmileView software. As observed in Figure 3(a), native sago starch comprised of smooth oval granules with a mean granule size of $20 \mu \mathrm{m}$. The sizes of the starch granules 
are ranging from $12 \mu \mathrm{m}$ to $27 \mu \mathrm{m}$. Figure 3(b) shows the SEM micrograph of amino-starch nanoparticles with the mean particle sizes of $163 \mathrm{~nm}$, and the size ranges at 120-200 $\mathrm{nm}$. The drastic change in the morphological characteristics of the starch granules was due to the pressure-induced by high-speed stirring and the reaction temperature of $70^{\circ} \mathrm{C}$ used during the modification process which destroyed the granule structures of the native starch. High-speed stirring during the precipitation process had resulted in the formation of small particle sizes by breaking apart aggregates or preventing particles from agglomerating. The aminostarch nanoparticles were observed to be spherical in shape.
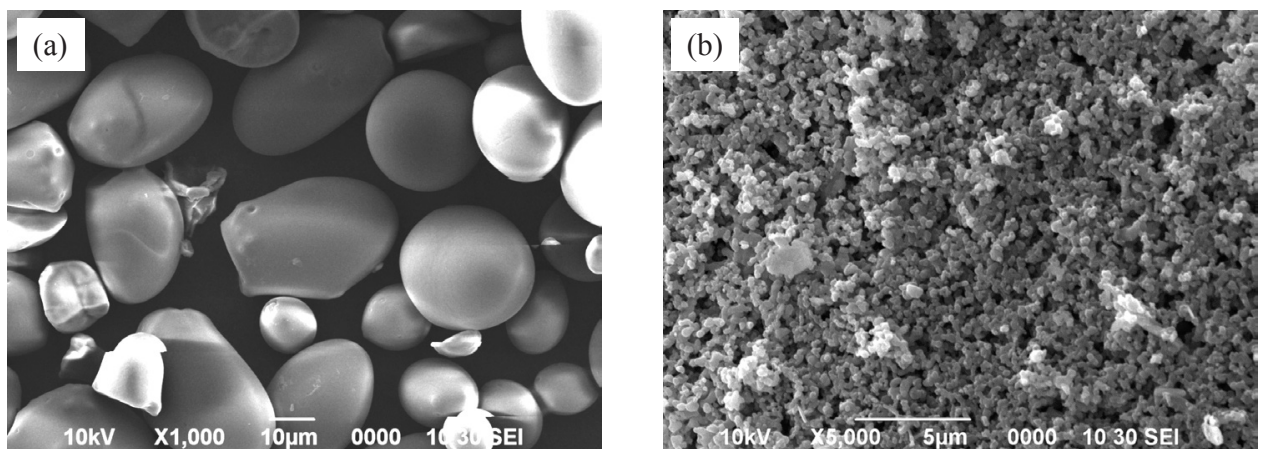

Figure 3: SEM micrographs of (a) native sago starch, and (b) amino-starch nanoparticles.

\subsection{Loading Capacity of Curcumin}

Curcumin was loaded onto amino-starch nanoparticles by the in-situ nanoprecipitation processes. The loading of curcumin occurred during the precipitation of starch nanoparticles, where curcumin was being encapsulated or adsorbed on the surface of regenerated nanoparticles. ${ }^{1}$ Figure 4 shows the loading capacity of curcumin increased linearly as the concentration of curcumin was increased from $0.5 \mathrm{mg}^{-1}$ to $5.0 \mathrm{mg} \mathrm{l}^{-1}$. At the concentration of $5 \mathrm{mg} \mathrm{l}^{-1}$ and above, the loading capacity of curcumin in the reaction medium was leveled off, indicating that the maximum loading has been achieved. The maximum loading capacity of curcumin for amino- starch nanoparticles was determined to be $0.76 \mathrm{mg} \mathrm{mg}^{-1}$.

In our previous finding, the maximum loading capacity of curcumin was $2.0 \mathrm{mg} \mathrm{mg} \mathrm{m}^{-1}$ with $78 \%$ loading efficiency in the microemulsion system. ${ }^{1}$ Much lower loading curcumin was reported in ethanolic solution with a loading efficiency of $13 \%$ and a maximum loading capacity of $0.33 \mathrm{mg} \mathrm{mg}^{-1}$. The loading of curcumin in the microemulsion system was higher due to the presence of highly hydrophobic of lipophilic domains in the system. The highly 
hydrophobic component further dissolved curcumin as it increased its solubility, thus improving the loading capacity of curcumin. In this work, a higher loading capacity was achieved in the ethanolic system as compared to a similar system used in the previous study. Enhanced solubility of the amino-starch not only led to the formation of a much stable starch solution but also enhanced the solubility of curcumin thereby resulted in a higher loading capacity of curcumin. The amine group worked almost similar to the lipophilic domain in the microemulsion system. The positively charged amino groups attached to the starch surface formed hydrogen bonds with the phenolic group of curcumin, resulting in the higher solubility of curcumin and hence led to the higher loading capacity at $0.76 \mathrm{mg} \mathrm{mg}^{-1}$ of curcumin onto the amino-starch nanoparticles compared to the loading capacity of $0.33 \mathrm{mg} \mathrm{mg}^{-1}$ in an ethanolic solution using native starch. ${ }^{16}$

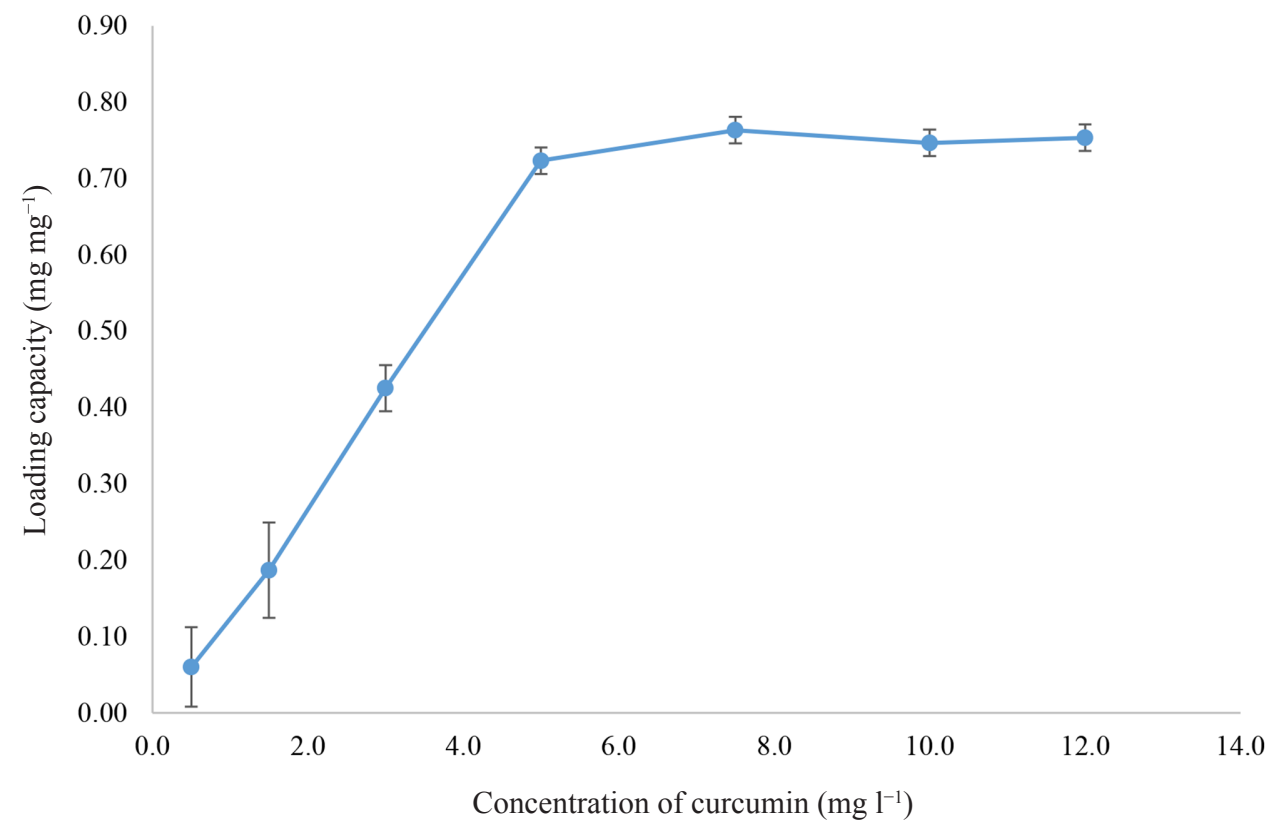

Figure 4: Effect of curcumin concentration in the reaction medium on the loading capacity of amino-starch nanoparticles (error bars were calculated from the mean value of triplicate readings, number of samples $(\mathrm{n})=3)$.

\subsection{Swelling Study}

Figure 5 shows the swelling behaviour of amino starch nanoparticles at $\mathrm{pH} 1.2$ and $\mathrm{pH}$ 7.4. It was observed that the swelling of nanoparticles increased along with the increase in time. Amino-starch nanoparticles showed that it swelled more at $\mathrm{pH} 1.2$ as compared to at $\mathrm{pH} 7.4$ medium. It is most likely that in acidic condition, 
which due to the protonation of the amine group attached on the surface of the nanoparticles. This has increased the positive charge density of the nanoparticles, thus facilitated repulsions between the polymer chains. ${ }^{2}$ Meanwhile, in the neutral condition of $\mathrm{pH} 7.4$, the amine group was not easily protonated as there is a lower amount of free proton available. Therefore, amino-starch nanoparticles swelled more in acidic conditions due to the protonation of the amine group on the polymeric chain.

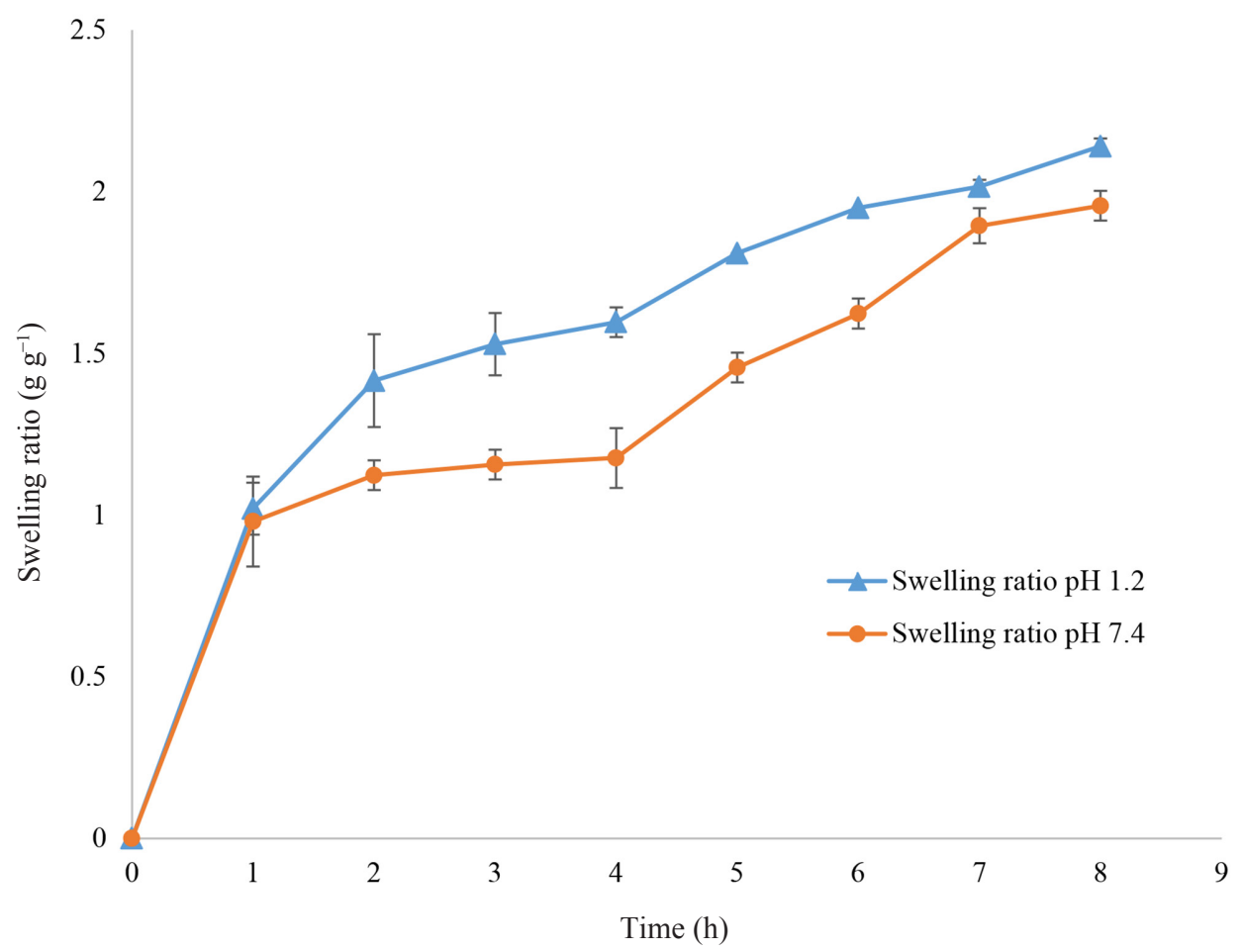

Figure 5: The swelling ratio of amino-starch nanoparticles at $\mathrm{pH} 1.2$ and $\mathrm{pH} 7.4$ (error bars were calculated from the mean value of triplicate readings, number of samples $(\mathrm{n})=3$ ).

\subsection{Curcumin Release Studies}

Curcumin release study was conducted in a phosphate buffer solution of $\mathrm{pH} 1.2$ and $\mathrm{pH} 7.4$ which simulate human digestive juice and blood, respectively. ${ }^{8}$ As can be seen in Figure 6, the release behaviour of curcumin from the amino-starch nanoparticles was closely influenced by time, swelling properties as well as the $\mathrm{pH}$ of the media. Curcumin is being released as the nanoparticles swelled up due to the absorption of the buffer solution, in which the swollen part facilitated the 
diffusion of curcumin gradually. As time increased, a higher degree of swelling allows greater access for the solution media to the encapsulated drug, therefore promote more the release of curcumin. ${ }^{1-3,7}$ The initial burst of curcumin released was observed within $2 \mathrm{~h}$ to be around $34 \%$ at $\mathrm{pH} 1.2$ and $36 \%$ at $\mathrm{pH} 7.4$ which brings the cumulative release close in between the two mediums. Despite the initial burst, curcumin continued to be released gradually at $\mathrm{pH}$ 7.4. At lower $\mathrm{pH}$, curcumin was released more within a shorter period compared to that at higher $\mathrm{pH}$. As shown in Figure 6, 100\% of curcumin were released within $8 \mathrm{~h}$ at $\mathrm{pH}$ 1.2. Meanwhile, at $\mathrm{pH} 7.4$, the loaded curcumin was fully released in $12 \mathrm{~h}$. This is because the nanoparticles swelled more in acidic conditions due to higher protonation of the attached amine group, thus promoting higher diffusion of curcumin. In short, the prepared amino-starch nanoparticles with its $\mathrm{pH}$-sensitive mechanism and controlled release of curcumin may be beneficial in various kinds of treatment, especially in cancer therapy for selective and efficient treatment. ${ }^{17}$

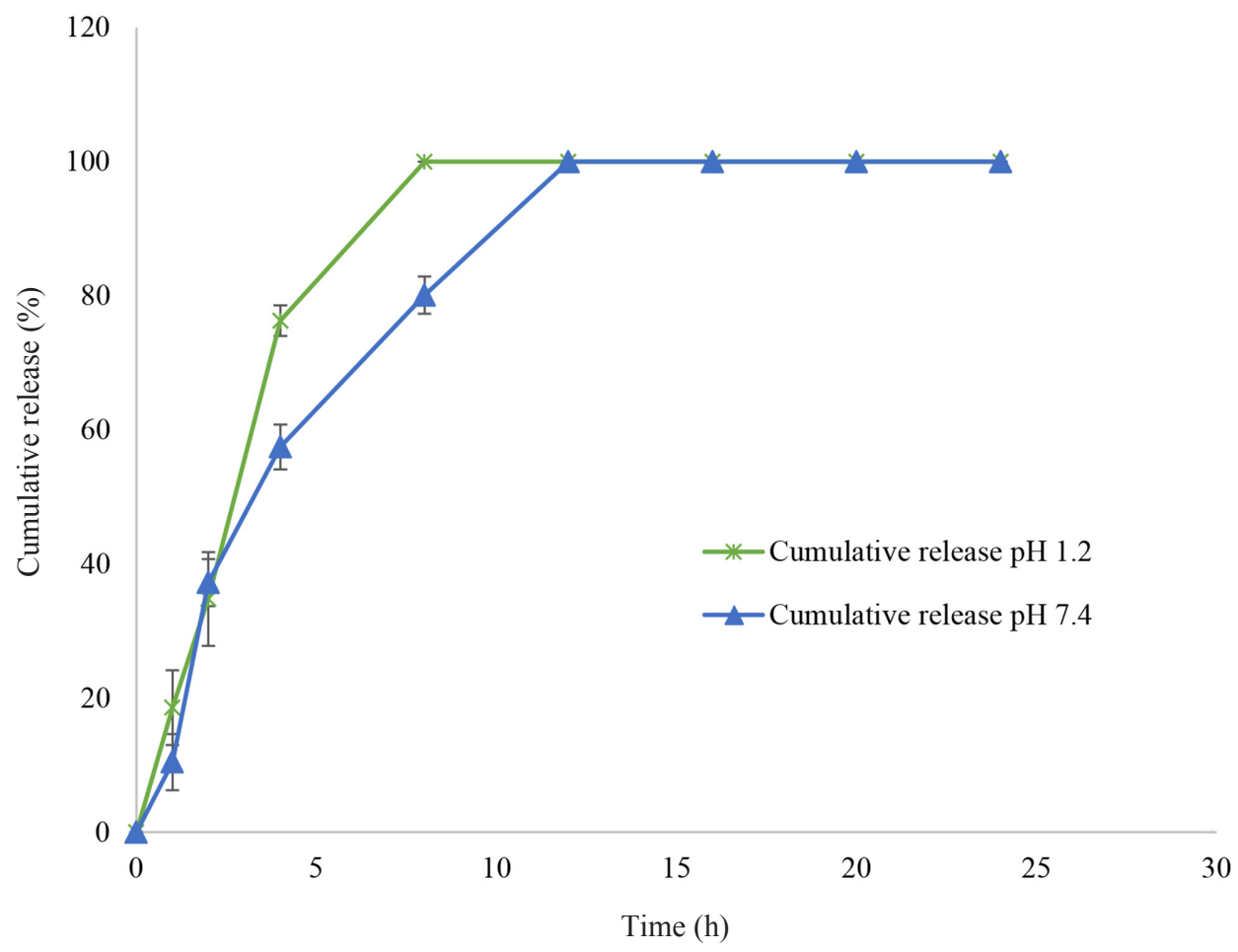

Figure 6: Cumulative release of curcumin from amino-starch nanoparticles at $\mathrm{pH} 1.2$ and $\mathrm{pH} 7.4$ (error bars were calculated from the mean value of triplicate readings, number of samples $(n)=3)$. 


\subsection{Drug Release Mechanism}

The drug release mechanism was studied by fitting into several kinetic models as shown in Table 1. The curcumin release profile on both $\mathrm{pHs}$ was found to closely correlate to zero-order and first-order as the linear regression coefficients $\left(\mathrm{R}^{2}\right)$ of curcumin were nearly 1 with $\mathrm{R}^{2}$ value in the range of $0.9022-0.9754$. This indicated that the curcumin release from amino-starch nanoparticles was concentration-independent. ${ }^{4}$ The in-vitro release data also showed a good fit for the Hixson-Crowell and Higuchi model ( $\mathrm{R}^{2}$ value of $\left.0.9318-0.9896\right)$, which could be attributed to the release profile based on swelling and erosion of the starch matrix. ${ }^{18}$ The release profile of curcumin from amino-starch nanoparticles was further clarified by applying the Korsmeyer-Peppas model. The $\mathrm{R}^{2}$ values from fitting the Korsmeyer-Peppas model were determined to be 0.9702 and 0.9028 at $\mathrm{pH} 1.2$ and 7.4, respectively, indicating that the release of curcumin was driven by diffusing out from the nanoparticles matrix. ${ }^{19}$ Amino-starch nanoparticles also showed a good fit for the model with the slope (n) value determined to be 0.8433 and $0.8404(\mathrm{pH} 1.2$ and 7.4) which falls in the range of 0.5-1.0. This implied that the release of curcumin is governed under a non-Fickian release profile. Therefore, as the (n) value shows that the curcumin release is nearly zero-order, anomalous, a non-Fickian release profile, it indicates that the drug transportation mechanism is by the combination of diffusion and erosion of the nanoparticles polymer chain. ${ }^{20}$ After fitting and comparing it into several kinetic models, the release of curcumin at $\mathrm{pH} 1.2$ was determined to closely correlate with the Hixson-Crowell model, as it shows the highest $\mathrm{R}^{2}$ value. This implies that the release was primarily due to surface erosion and swelling of the nanoparticles. Meanwhile, at $\mathrm{pH} 7.4$ the release profile of curcumin obeys Higuchi kinetic models, indicating that the drug is mainly released by diffusion mechanism.

Table 1: Kinetic modeling of curcumin release from amino-starch nanoparticles.

\begin{tabular}{lccl}
\hline Kinetic models & $\mathrm{pH}$ & Regression coefficient $\left(\mathrm{R}^{2}\right)$ & \multicolumn{1}{c}{ Features } \\
\hline Zero order & 1.2 & 0.9155 & $\begin{array}{l}\text { Concentration independant rate } \\
\text { of release }\end{array}$ \\
First-order & 7.4 & 0.9210 & $\begin{array}{l}\text { Concentration dependent rate } \\
\text { of release }\end{array}$ \\
Hixson-Crowell & 1.2 & 0.9754 & Surface erosion and swelling \\
& 7.4 & 0.9022 & drug release mechanism \\
Higuchi & 1.2 & 0.9896 & Diffusion release mechanism \\
& 7.4 & 0.9318 & \\
Korsmeyer-Peppas & 1.2 & 0.9661 & Diffusion and swelling release \\
& 7.4 & 0.9766 & mechanism \\
\hline
\end{tabular}




\section{CONCLUSION}

Curcumin loaded amino-starch nanoparticles were successfully prepared. The amino-starch exhibited higher solubility in aqueous solution forming a stable suspension. Amino-starch nanoparticles demonstrated a substantially higher loading capacity of curcumin of $0.76 \mathrm{mg} \mathrm{mg}^{-1}$ as compared to that of native starch nanoparticles of $0.33 \mathrm{mg} \mathrm{mg}^{-1}$. The release of curcumin at $\mathrm{pH} 1.2$ was also found to be correlated with Hixson-Crowell model, while at $\mathrm{pH} 7.4$ the release profile obeyed Higuchi kinetic models. This showed that at $\mathrm{pH} 1.2$ the release of curcumin is based on surface erosion and swelling of the nanoparticles, but at $\mathrm{pH} 7.4$ the drug was mainly released by diffusing out of the nanoparticles. Overall, this study has demonstrated that amino-starch nanoparticles are promising nanocarriers for the controlled release of curcumin.

\section{ACKNOWLEDGEMENTS}

The authors wish to acknowledge the financial support rendered by the Malaysia's Ministry of Education via the Fundamental Research Grant Scheme (grant no. F07/FRGS/1495/2016).

\section{REFERENCES}

1. Chin, S. F. et al. (2014). Preparation and characterization of starch nanoparticles for controlled release of curcumin. Int. J. Polym. Sci., 1-8, article ID 340121. https://doi.org/10.1155/2014/340121.

2. Saikia, C. et al. (2017). Evaluation of folic acid tagged aminated starch/ZnO coated iron oxide nanoparticles as targeted curcumin delivery system. Carbohydr. Polym., 157, 391-399. https://doi.org/10.1016/j.carbpol.2016.09.087

3. Chin, S. F. et al. (2009). Encapsulation and sustained release of curcumin using superparamagnetic silica reservoirs. Chem. Eur. J., 15(23), 5661-5665. https://doi.org/10.1002/chem.200802747

4. Chin, S. F. et al. (2019). pH-responsive starch-citrate nanoparticles for controlled release of paracetamol. Starch/Stärke, 1800336, 1-9. https://doi.org/10.1002/ star.201800336

5. Lozano-Navarro, J. I. et al. (2017). Antimicrobial, optical and mechanical properties of chitosan-starch films with natural extracts. Int. J. Mol. Sci., 18(5), 1-18. https://doi.org/10.3390/ijms18050997

6. Wang, W. et al. (2010). Optimized conditions in preparation of giant reed quaternary amino anion exchanger for phosphate removal. Chem. Eng. J., 157(1), 161-167. https://doi.org/10.1016/j.cej.2009.11.024 
7. Voon, L. K. et al. (2017). Optimizing delivery characteristics of curcumin as a model drug via tailoring mean diameter ranges of cellulose beads. Int. J. Polym. Sci., 1-10, article ID 2581767. https://doi.org/10.1155/2017/2581767

8. Gaur, P. K. et al. (2014). Formulation and evaluation of controlled-release of telmisartan microspheres: in vitro/in vivo study. J. Food Drug Anal., 22(4), 542548. https://doi.org/10.1016/j.jfda.2014.05.001

9. Russell, T. L. et al. (1993). Upper gastrointestinal $\mathrm{pH}$ in seventy-nine healthy, elderly, north american men and women, Pharm. Res., 10(2), 187-196. https://doi.org/10.1023/a:1018970323716

10. Tang, H. et al. (2009). A starch-based biodegradable film modified by nano silicon dioxide. J. Appl. Polym. Sci., 113(1), 34-40. https://doi.org/10.1002/app.29855

11. El-hamshary, H. et al. (2006). Synthesis and biological study of some amino acid functionalized starch-graft-polyacrylamide. Carbohydr. Polym., 64(2), 282-286. https://doi.org/10.1016/j.carbpol.2005.11.036

12. Dong, A. et al. (2010). A novel method for amino starch preparation and its adsorption for $\mathrm{Cu}$ (II) and $\mathrm{Cr}$ (VI). J. Hazard. Mater., 181(1-3), 448-454. https://doi.org/10.1016/j.jhazmat.2010.05.031

13. Shahzadi, K. et al. (2015). Preparation and characterization of bio-based hybrid film containing chitosan and silver nanowires. Carbohydr. Polym., 137, 732-738. https://doi.org/10.1016/j.carbpol.2015.11.012

14. Šimkovic, I. (1996). Preparation of a weakly basic ion exchanger by crosslinking starch with epichlorohydrin in the presence of $\mathrm{NH}_{4} \mathrm{OH}$. Carbohydr. Polym., 30(1), 25-30. https://doi.org/10.1016/S0144-8617(96)00060-4

15. Biçaak, N. \& Senkal, B. F. (1996). Removal of nitrite ions from aqueous solutions by the cross-linked polymer of ethylenediamine with epichlorohydrin. React. Funct. Polym., 36(1), 71-77. https://doi.org/10.1016/S1381-5148(97)00122-3

16. Taebnia, N. (2016). Curcumin-loaded amine-functionalized mesoporous silica nanoparticles inhibit the $\alpha$-synuclein fibrillation and reduce its cytotoxicityassociated effects. Langmuir, 32(50), 13394-13402. https://doi.org/10.1021/acs .langmuir.6b02935

17. Manatunga, D. C. et al. (2017). pH-responsive controlled release of anti-cancer hydrophobic drugs from sodium alginate and hydroxyapatite bi-coated iron oxide nanoparticles. Eur. J. Pharm. Biopharm., 117, 29-38. https://oi.org/10.1016/ j.ejpb.2017.03.014

18. Baishya, H. (2017). Application of mathematical models in drug release kinetics of carbidopa and levodopa ER tablets. J. Dev. Drugs, 6(2), 1-8. https://doi.org/ 10.4172/2329-6631.1000171

19. Voon, L. K. et al. (2017). Porous cellulose beads fabricated from regenerated cellulose as potential drug delivery carriers. J. Chem., 1-11, article ID 1943432. https://doi.org/10.1155/2017/1943432

20. Shah, K. U. \& Khan, G. M. (2012). Regulating drug release behavior and kinetics from matrix tablets based on fine particle-sized ethyl cellulose ether derivatives: An in vitro and in vivo evaluation. Sci. World J., 1-8, article ID 842348. https://doi.org/10.1100/2012/842348 